
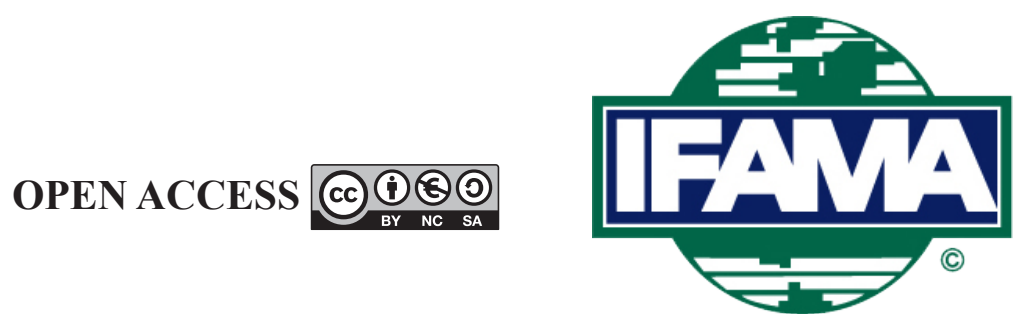

International Food and Agribusiness Management Review

Volume 24, Issue 2, 2021; DOI: 10.22434/IFAMR2020.0009

Received: 24 May 2019 / Accepted: 12 February 2020

Special track: European agrifood business in transition towards social responsibility

\title{
Conception and evaluation of a structural equation model to measure the reputation of German horticulture
}

\section{RESEARCH ARTICLE}

\author{
Marike Isaak $^{\circledR a}$, Iris Brenneke ${ }^{\mathrm{a}}$ and Wolfgang Lentz ${ }^{\mathrm{b}}$ \\ ${ }^{a}$ MSc, Center for Business Management in Horticulture and Applied Research, Institute of Horticultural \\ Production Systems, Leibniz University Hanover, Herrenhaeuser Str. 2, 30419 Hannover, Germany \\ ${ }^{b}$ Prof. Dr., Faculty of Agriculture/Environment/Chemistry, University of Applied \\ Sciences Dresden (HTW Dresden), Pillnitzer Platz 2, 01326 Dresden, Germany
}

\begin{abstract}
The reputation of a sector is an important strategic resource. The aim of this article is to develop a measurement model for the horticulture sector. Reputation is a latent variable and is represented by formative and reflective indicators. A theoretically elaborated model will be evaluated and completed with the help of experts $(\mathrm{n}=102)$, and the segments that influence reputation will be identified. The quality assessment of the formative indicators, using multiple regression, and the reflective indicators, using an explorative factor analysis, led to a model with a total of 15 indicators. With the help of open questions, it was possible, to specify the indicators already considered or to include them in the model as new indicators. A reputation map shows the interaction between the reputation of horticulture and that of the individual segments. This shows a much greater influence of the service segments on the sector reputation compared to the production segments.
\end{abstract}

Keywords: horticulture, reputation, formative, reflective, reputation measurement JEL code: Q13

\footnotetext{
(i)Corresponding author: isaak@zbg.uni-hannover.de
} 


\section{Introduction}

Horticulture is a branch of agriculture which deals with the principles and practices of growing vegetables, fruits and flowers (Lal, 2008: 19). Horticulture as a sector is characterized by great heterogeneity. It can be divided into the areas of horticultural production, services and trade. Horticultural production is further subdivided into the fruit, vegetable, ornamental plant and nursery segments. A large number of different products are produced in these segments. The service and retail segments include garden and landscaping, cemetery horticulture, retail and floristry. Public green areas, such as parks or garden shows, can also be regarded as horticultural products.

The reputation of horticulture as a sector among stakeholders can only be speculated upon. As early as the 1990s, expert circles already pointed to the early development of image improvement activities for horticulture in order to consolidate the standing and position of horticulture (Storck, 1992). Ludwig-Ohm and Dirksmeyer (2013: 30) report a frequently observed skepticism among the population particularly towards horticultural production systems. Technological progress in production has led to a gap between the consumer's ideas and actual production methods. Today, more than ever, environmental aspects are perceived by consumers and can therefore also influence purchasing decisions for horticultural products (Meyerding, 2016: 132). In addition, many horticultural products have confidence characteristics (e.g. taste) that cannot be tested at the point of sale. Trust in these products can be influenced by the reputation of the sector (Weigelt and Camerer, 1988). Due to the lack of differentiation of the products, the sector's reputation can also be damaged by opportunistic behavior of individual producers (Winfree and McCluskey, 2005: 207). A bad reputation can result in a decline in sales and thus influence the economic success of a company. Bitsch et al. (2014: 110) were able to show that the occurrence of foodborne illnesses leads to economic losses and a reputation damage.

In combination with customer loyalty and identification, reputation can lead to an improvement in the intention to buy and the willingness to pay, thus influencing sales in the sector (Keh and Xie, 2009). Reputation is therefore an important strategic resource for companies. This influences communication with stakeholders and legitimizes entrepreneurial action (Sageder et al., 2018: 351-352). Nevertheless, no measurement approach is known that captures the reputation of horticulture in all its diversity. Only on the basis of a measurement approach it will be possible to formulate concrete recommendations for the entire sector and the individual segments on how reputation can be influenced. This missing measurement approach will be elaborated in this publication.

An approach for reputation measurement based on a literature research is to be adapted by experts with the aim of carrying out a consumer survey in the following step. The validation of the indicators of a structural model by experts is the declared aim of the present work. These indicators have been used in non-sector-specific measurement systems for companies and sectors, which requires adaptation to the specific characteristics of horticulture. Besides, validation by experts is necessary, because the model should be corrected for possible incompleteness and unsuitable indicators should be eliminated (Rossiter, 2002: 308-309; Schwaiger, 2004: 57; Straub, 1989: 150; Zinnbauer and Eberl, 2004: 9). The main research question that should be answered in this paper is, what indicators describe the reputation of horticulture.

With the help of the experts, the interaction between the reputation of horticulture and the reputation of the individual segments can also be investigated. The second research question is whether the reputation of horticulture is mainly influenced by segments and what is the relative contribution of the segments to the sector's reputation from an expert perspective. With the help of experts, it will be examined whether certain sectors have a higher presence in the minds of consumers (society). It is assumed, for example, that visiting public parks or creating private gardens by the horticultural and landscaping contractors, this segment makes a higher contribution to the reputation of the entire sector. 


\section{Theoretical framework}

Reputation is defined by Fombrun as 'a perceptual representation of a company's past actions and future prospects that describes the firm's overall appeal to all of its key constituents when compared with other leading rivals' (Fombrun, 1996: 72). This has been the most commonly used definition since the mid-1990s. (Wartick, 2002: 374). As also stated in this paper, reputation in scientific research is mostly understood and treated as a synonym for the terms reputation and standing (Hautzinger, 2009: 13-15; Helm, 2007c: 20; Liebert, 2009: 3839; Schwalbach, 2003: 227). The frequently used German term 'Ruf' is described by Breyer (1962) as a short, clear, characteristic and (relatively) constant statement about an object of opinion (Breyer, 1962: 63 cited after Helm, 2007b: 20). Reputation at sector level is understood in the sense of Helm (2007c: 270) as an opinion that dominates in the public eye. Simply put, reputation was defined here as the recognized performance and willingness of the company to perform, which other authors also call 'organizational performance' (Boyd et al., 2010: 2; Fombrun and Shanley, 1990: 255; Helm, 2007c: 46; Roberts and Dowling, 2002: 1078). Following Hautzinger (2009: 34), this view of corporate reputation is transferred to the sector. The sector's reputation is thus understood as the public recognition perceived by stakeholders of the sector's performance and willingness to perform (Luoma-aho, 2008: 450). Performance includes all the activities of a sector, in terms of both economic and social factors (Lins et al., 2017: 1820).

Reputation is a latent construct that is not directly observable in this form (Joreskog and Goldberger, 1975: 631). Only through its relationships to observable (to be interrogated) variables, which are also called indicators or items, does it become measurable (Fornell and Bookstein, 1982: 441; Helm, 2007c: 130; Joreskog and Goldberger, 1975: 631; MacMillan et al., 2005: 222). The construct reputation thus forms the latent variable, which in turn, is described by the variables assigned to it - the indicators or items. The complexity of the construct is shown in the literature through the lack of consensus on which aspects the reputation actually covers and in the multitude of approaches to reputation measurement (Davies et al., 2001: 114-115).

The multiple indicators and multiple causes (MIMIC) model were selected as the approach to reputation measurement (Figure 1). This model makes it possible to evaluate the indicators used as a whole (i.e. taking into account their interrelations) and requires the inclusion of reflective indicators in addition to the formative ones (Diamantopoulos and Winklhofer, 2001: 272; Hauser and Goldberger, 1971: 95-97; Joreskog and Goldberger, 1975: 631). The formative indicators represent the direct causes of the latent variable, while the variable is indicated by one or more reflective indicators (Diamantopoulos and Winklhofer, 2001: 272).

\section{Research method}

In the first research stage, the literature analysis, fundamental findings on reputation as a latent variable and on the measurement of reputation were first collected and incorporated into a theoretical model for measuring reputation.

Systems for measuring corporate reputation, such as the reputation quotient or the fortune system, are already being used in business. A reputation measurement at sector level, using the example of the automotive sector, on the other hand, was only carried out within the framework of a scientific study. Based on these existing measurement approaches for companies as well as for sectors, indicators from eight systems were analyzed, compared, tabulated and subsumed. The indicators were brought together in the form of a MIMIC model (Figure 1).

In the second stage of the study described here, the model is validated, as the results of empirical studies have shown that many country- and sector-specific peculiarities have to be taken into account (Wiedmann et al., 2007: 14). To validate and supplement the set of indicators, qualitative and quantitative methods were combined in a questionnaire in the form of a mixed method approach. The indicators summarized in the model were quantitatively tested on a 7-point Likert scale with regard to their suitability for horticulture. The structure of the questionnaire follows the study by Hautzinger (2009). The global measure required for the statistical 


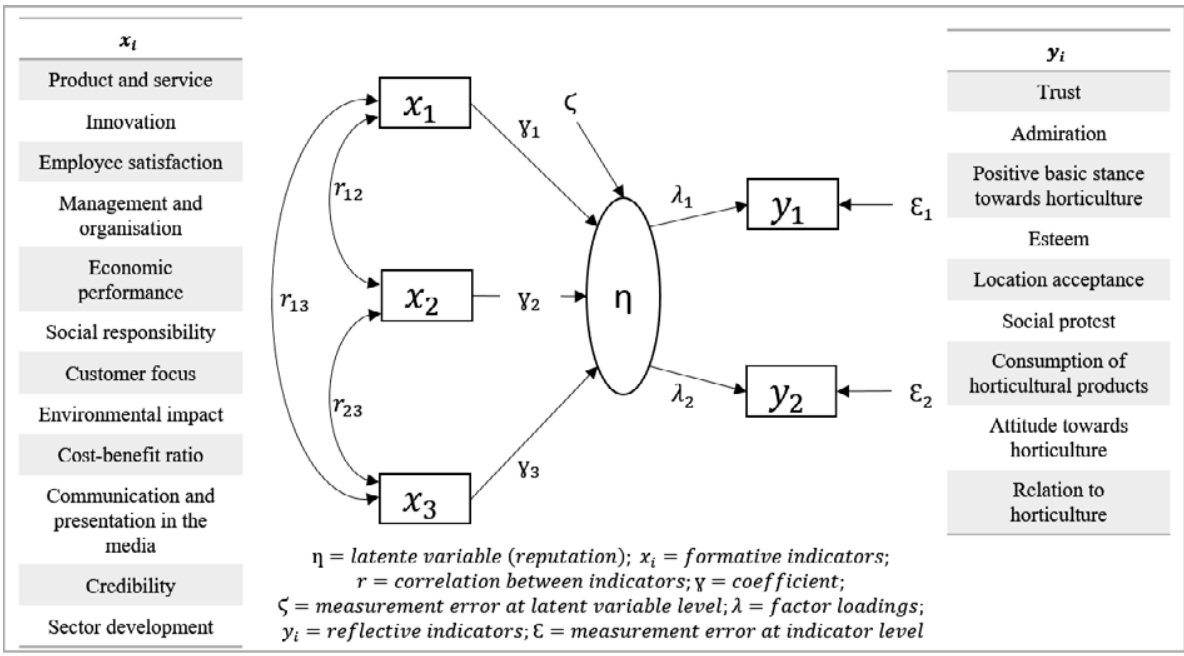

Figure 1. Proposed structural model for measuring the reputation of the horticultural sector (adapted from Diamantopoulos and Winklhofer, 2001: 272).

quality check - the assessment of the reputation by the experts - was also determined on the basis of a 7-point Likert scale.

The interaction between the reputation of the segments and the reputation of the sector was also quantitatively analyzed in this part. By asking two questions with changing perspectives regarding the influence on the reputation, the importance of the different segments was also examined on a 7-point Likert scale. The explorative character of the study could be fulfilled by open questions. The use of qualitative methods in the form of open questions served to complete the set of indicators as well as to identify further areas that have a major influence on the reputation of horticulture.

The questionnaire was available online and was created using LimeSurvey (version 2.6.6). The evaluation of the closed questions was done by IBM SPSS Statistics 25 (IBM, Armonk, New York, NY, USA) and the evaluation of the open questions by MAXQDA Analytics Pro 2018 (VERBI GmbH, Berlin, Germany). In the third stage, the structural model is then used to survey the reputation among consumers.

\subsection{Quality criteria of formative indicators}

The reputation of a sector is defined as publicly recognized performance and willingness to perform. Based on this definition, the formative indicators represent the performance of a sector and thus justify the reputation of a sector (Helm, 2005: 99). The formative indicators can be regarded as building blocks of the reputation construct and their change leads to a change in reputation.

The evaluation of the formative indicators in the construct is based on multiple regression (Diamantopoulos et al., 2008: 1205). The regression coefficient gives information about the validity of the indicators regarding the construct.

The set of indicators represents the construct (Steinmann, 2013: 136). Strong multicollinearity - a linear interdependence of indicators - should be excluded, since each individual indicator should contribute independently to reputation. The variance inflation factor (VIF) can be used to describe the strength of the dependence of a single indicator on the other construct indicators. A VIF value of one illustrates the complete linear independence of the indicators (Gujarati, 2004: 351), while a VIF value $>10$ is considered critical (Diamantopoulos et al., 2008: 1212). In order to avoid distortion in a small sample, the VIF value $>3.3$ is defined as the limit value, as has already been the case in other studies (Diamantopoulos and Siguaw, 2006: 270; Hautzinger, 2009: 228). 
A $t$-test can be used to determine the significance of the indicators for the construct. However, a value of nonsignificance does not automatically result in the elimination of an indicator. Different views are expressed in the literature on dealing with non-significant indicators (cf. Diamantopoulos and Siguaw, 2006: 270; Helm, 2005: 251). For this work, the correlation with the global measure is used as the elimination criterion (Helm, 2007c: 298). Correlation with the global measure ensures that there is a connection between the indicator and the latent variable (Diamantopoulos and Winklhofer, 2001: 272).

\subsection{Quality criteria of reflective indicators}

The reflective indicators represent the sector's reputation. Reputation can thus be described as a function of reflective indicators and a change in reputation results in a change of the assigned reflective indicators.

The indicator reliability provides information on the suitability of the indicator for the description of the latent variable. The unidimensionality can be proven by explorative factor analysis and the reliability of the indicator for the construct is described by the height of the indicator loadings. An indicator loading of 0.7 is considered acceptable (Huber et al., 2003: 89; Schöps, 2012: 181). This limit can be used to ensure that the variance of an indicator caused by the construct is higher than the variance caused by the measurement error. Indicators that do not reach this loading are eliminated from the construct. The loadings are tested for significance by a one-sided $t$-test at 5\% level (>1.645) (Huber et al., 2003: 35).

The construct reliability (CR) can also be called factor reliability or internal consistency and is the degree of explanation for the relationship between the indicators and the construct. To ensure that the indicators reflect the construct as well as possible, a strong correlation between the indicators is desired. A value of $>0.7$ is targeted for a strong link or high homogeneity of the indicators (Hautzinger, 2009: 235; Huber et al., 2003: 35).

Another measure of the internal consistence is Cronbach's alpha with a limit of 0.7 (Peterson, 1994: 388). However, Nitzel (2010: 26) points out that Cronbach's alpha tends to underestimate internal consistence, which is why both CR and Cronbach's alpha are used as quality criteria in the following.

A further validity check can be carried out with the use of the average variance extracted (AVE). This describes the ratio of the measurement portion explained by the latent variable to the measurement error. For this purpose, at least half of the variance of the indicators of a construct should be explained by the latent variable (Hautzinger, 2009: 235; Johanna Schöps, 2013: 69).

In addition, discriminant validity can be used to examine the differences between the indicators of this construct and those of another construct. According to the Fornell-Larcker criterion, the AVE should be higher than any correlation of this latent variable with another latent variable (Fornell and Larcker, 1981: 45; Nitzl, 2010: 27).

\subsection{Reputation characteristics specific to horticulture}

The evaluation of the free texts is based on a qualitative content analysis according to Mayring and is based on the methodology for inductive category formation. The statements of the experts on the formation of upper categories are used. If further differentiation appears to make sense, the upper categories are segmented into further subcategories (Mayring, 2014: 106). At this point, the experts were asked to name other characteristics that had not been adequately addressed or completely disregarded so far, and which have a decisive influence on the reputation of horticulture in society. The aim of this approach is to identify horticultural-specific characteristics to supplement the construct and to further specify the indicators collected from the literature.

First, the category system was defined (selection criterion) and the level of abstraction fixed (depth), which is used as a guideline in the further course of category formation. In an iterative process, statements, sentences 
or individual words (keyword-like enumerations) were subsumed under already existing categories or new categories were created from the material, taking into account category definitions and abstraction level.

A formative reliability test was carried out by revising the categories according to $50 \%$ of the material. The summative reliability test was finally fulfilled by a final passage through the material.

\subsection{Sample structure}

The target group of the survey are experts who work as consultants in the horticultural sector. Consultants are closely linked to the sector and represent an interface between the internal and external viewpoints. The internal view of the sector includes extensive knowledge of the special features of the sector that they have collected through their professional experience. On the other hand, their employment or self-employment as consultants enables them to take an external perspective of the sector. Besides they are not economically directly dependent on the success of the horticultural business and can independently assess sector-specific characteristics. Additionally, the consultants can also evaluate characteristics of horticulture from a consumer perspective.

The contact data of associations, institutes, chambers of agriculture and consulting firms were determined by online research. The approach was differentiated according to federal states. The experts (132) were contacted via email with a link to the survey and a request to forward the study. With this procedure a distribution could be achieved by a snowball effect. After 14 days, a second email was sent as a reminder. The survey took place from the beginning of May to the middle of July 2018.

A total of 102 questionnaires, fully completed by experts, were collected in this way. $77 \%$ of the experts carry out their work in associations, research institutes, teaching and research institutes or public authorities. $41 \%$ of the respondents are active in cross-divisional consulting services regardless of the segments. Some respondents are only active in one segment of the sector (agriculture $8 \%$; retail and floristry 3\%). 15\% of the respondents are active in vegetable growing, $11 \%$ in fruit growing, $10 \%$ in gardening and landscape construction and $9 \%$ in ornamental horticulture.

\section{Results}

The quality assessment of the formative and reflective indicators was carried out with the help of the global measure. The global measure, which raises the reputation of the sector from the perspective of the experts irrespective of the indicators, indicates a slightly positive trend $(\mu=4.4)(n=102)$. However, the distribution also shows that only eight surveyed experts rated the reputation as very bad (1) or bad (2). On the other hand, according to the assessment of 6 experts, the sector's reputation is even very good (7).

As reputation is a collective image created through interaction with third parties, the experts were not given a definition of the indicators (Petty and Cacioppo, 1983: 143). Thus, the following evaluation of the indicators only reflects the respondents' understanding of the indicators, which is shaped by the public.

\subsection{Quality testing of formative indicators}

All indicators which are directly related to corporate activities and in their sum reflect the sector activities, form the reputation of the sector and can thus be operationalized in a formatively effective direction. The formative link thus describes a cause-effect relationship between the observations (indicators) and the latent construct (reputation).

Overall, the formative indicators make only a negligible weak contribution to the regression equation (Table 1). The indicator 'Environmental impact' has the highest effect on reputation and is the only one which has a 
Table 1. Quality testing: regression of formative indicators $(n=102) .{ }^{1}$

\begin{tabular}{llcccl}
\hline Indicators & Mean value & $\begin{array}{l}\text { Estimated } \\
\text { coefficient }\end{array}$ & t-value & VIF $^{\mathbf{2}}$ & $\begin{array}{l}\text { Correlation with the } \\
\text { global measure }\end{array}$ \\
\hline Innovation & 3.775 & -0.098 & -0.95 & 1.340 & 0.471 \\
Customer focus & 5.169 & 0.177 & 1.33 & 1.419 & 0.177 \\
Employee satisfaction & 3.674 & -0.152 & -1.51 & 1.400 & 0.165 \\
Economic performance & 3.596 & -0.006 & -0.04 & 2.184 & 0.336 \\
Sector development & 3.584 & 0.144 & 1.05 & 2.423 & 0.146 \\
Social responsibility & 4.685 & 0.057 & 0.54 & 1.592 & 0.392 \\
Environmental impact & 5.674 & -0.235 & $-1.9 * *$ & 1.645 & 0.157 \\
Communication and & 5.157 & 0.124 & 1.24 & 1.421 & 0.129 \\
presentation in the media & & $>0.1$ & $>1.645$ & $<3.3$ & $>10 \%$ \\
Critical values & & (one-tailed & & probability of error \\
& & test) & \\
\hline
\end{tabular}

${ }^{1} 1=$ 'not very influential' and $7=$ 'very influential'; $* *=5 \%$ significance level.

${ }^{2} \mathrm{VIF}=$ variance inflation factor.

statistically significant influence on the construct. The negative regression coefficient clearly shows that, in this construct, an increase in environmental pollution leads to a deterioration in the reputation of horticulture.

The indicators 'Innovation', 'Employee satisfaction' and 'Economic performance' also have a negative coefficient. An increase in the respective indicator results in a deterioration of reputation by the level of the coefficient. Since the contribution of the indicators 'Innovation' and 'Economic performance' to the regression equation is very small $(<0.1)$, the interpretation of the negative coefficient can be neglected. However, the negative coefficient of the indicator 'Employee satisfaction' indicates a deterioration of the reputation with increasing employee satisfaction. This surprising connection can probably be attributed to the rather secondary importance of the indicator 'employee satisfaction' for the experts.

The external validity - the correlation of the indicators with the global measure - ensures that the indicators are of relevance to the construct. The indicators 'Product and service', 'Cost-benefit ratio', 'management and organization' and 'credibility' were excluded from the formative construct due to a missing correlation with the global measure (reputation of horticulture).

\subsection{Quality testing of reflective indicators}

The reflective indicators evoked the observations in reality from the non-measurable construct (Helm, 2007c: 130). The reflective indicators present the consequences of reputation, which in turn is made up of the sum of the effects of the formative indicators (Diamantopoulos and Winklhofer, 2001: 272-273). The cause-effect relationship here thus runs from the construct in the direction of its indicators.

The indicator reliability can be tested on the basis of the factor loadings. The construct reputation explains a large share of the indicator's variance: 'Positive basic stance towards horticulture', 'Esteem', 'Location acceptance', 'Attitude towards horticulture', and 'Relationship to horticulture' (Table 2). For the indicator 'Consumption of horticultural products', the share of declared variance by construct is just below the required limit of 0.7. Since the common variance between indicator and construct (with over 0.5 ) is still higher than the variance of the measurement error, this indicator should continue to be taken into account due to its high content relevance. All indicator loadings fulfil the quality criterion of one-sided significance. The indicators 'Trust', 'Admiration' and 'Social protest' were eliminated from the construct because the factor loadings were too low. The reliability of the still considered indicators in the construct can be described as good with 
Table 2. Quality testing: factor analysis of reflective indicators $(\mathrm{n}=102)$.

\begin{tabular}{|c|c|c|c|c|c|c|c|}
\hline Indicators & $\begin{array}{l}\text { Mean } \\
\text { value }^{1}\end{array}$ & $\begin{array}{l}\text { Factor } \\
\text { loadings }\end{array}$ & $t$-value & $\mathrm{AVE}^{2}$ & $\mathrm{CR}^{2}$ & $\begin{array}{l}\text { Cronbachs } \\
\text { alpha }\end{array}$ & $\begin{array}{l}\text { Fornell- } \\
\text { Larcker }\end{array}$ \\
\hline $\begin{array}{l}\text { Positive basic stance } \\
\text { towards horticulture }\end{array}$ & 4.677 & 0.793 & 27.448 & \multirow{6}{*}{0.66} & \multirow{6}{*}{0.9} & \multirow{6}{*}{0.849} & \multirow{6}{*}{$\begin{array}{l}0.0974<\text { AVE } \\
\left(\mathrm{r}^{2}=0.3122\right. \\
2=0.0974)\end{array}$} \\
\hline Esteem & 4.248 & 0.821 & 25.383 & & & & \\
\hline Location acceptance & 4.022 & 0.806 & 25.894 & & & & \\
\hline $\begin{array}{l}\text { Consumption of } \\
\text { horticultural products }\end{array}$ & 5.188 & 0.694 & 37.490 & & & & \\
\hline $\begin{array}{l}\text { Attitude towards } \\
\text { horticulture }\end{array}$ & 4.632 & 0.805 & 28.364 & & & & \\
\hline Relation to horticulture & 4.907 & 0.764 & 28.291 & & & & \\
\hline Critical values & & $>0.7$ & $\begin{array}{l}>1.645 \\
\text { (one-tailed test) }\end{array}$ & $>0.5$ & $>0.7$ & $>0.7$ & $\mathrm{R}^{2}<\mathrm{AVE}$ \\
\hline
\end{tabular}

an alpha value of 0.849 . However, CR, which is used as a further instrument to ensure internal consistency, also exhibits a strong link (homogeneity) between the indicators and the latent variable. In contrast to the formative indicators, as already mentioned the reflective indicators must correlate strongly enough with each other. The convergence validity described by the AVE shows that a $66 \%$ share of variance is explained by the reflective measurement model. Thus, the declared share of variance due to reputation is higher than the measurement error. Using the Fornell-Larcker criterion it can be shown that the average variance of the construct reputation is higher than the squared correlation with another construct. In this way, the validity of the indicators for the construct 'reputation' can be assumed.

\subsection{Identification of reputation characteristics specific to horticulture}

The reputation indicators tested for their quality (see Sections 4.1 and 4.2) do not take into account any specific characteristics of horticulture due to their originating from existing reputation measurement systems (see Section 3). This is partly due to the universal orientation of the measurement systems, which are oriented towards sectors or companies that have little in common with the horticultural sector. Since sector-specific characteristics must be taken into account when measuring reputation (Wiedmann et al., 2007: 14), an open question is asked about specific reputation characteristics of the horticultural sector. As a consequence of the results, the construct should be extended accordingly by newly acquired features or through further specification of the already included indicators.

The procedure described in Section 3.3 resulted in a total of eight main categories (characteristics). Table 3 shows seven of these categories. The category 'Events $\&$ holidays/special occasions' has been omitted due to the unique naming. For each subcategory with $n \geq 4$ mentions, two statements are presented, which are rated as particularly significant for the respective characteristic or represent the diversity of the statements well. Subcategories with fewer mentions are characterized by one statement.

A total of 57 respondents provided information on this question. The answers to these free text questions were very detailed and well-founded. From the category 'Job description \& profession' $(n=17)$ two subcategories could be formed. Here it proved to be useful to differentiate between negative $(n=5)$ and positive $(n=6)$ associations with the occupational profile. In this way, the many facets of the statements could be precisely contrasted. The heterogeneity of the perceptions is reflected in the almost equal number of positive and negative statements. The importance of the category for reputation formation is also highlighted by the largest number of responses. However, it must also be considered that the frequency of mentions does not provide a reliable indication of 
Table 3. Summary of reputation characteristics specific to horticulture $(n=57)$.
Subcategories (n)
Coded text passages/coding

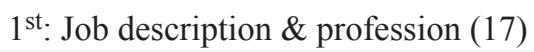

Negative (5)

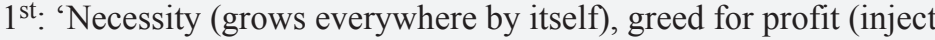
everything dead so that they earn as much money as possible).'

$2^{\text {nd: }}$ 'Poor working conditions, unhealthy, pesticidal contaminated work $[\ldots]$ '.

Positive (6)

$1^{\text {st: }}$ 'Professional expertise, conviction, lifeblood [...].'

$2^{\text {nd: }}$ ' $[\ldots]$ complexity of the profession, study is required, indicates high wages for the workforce.'

$2^{\text {nd: }}$ Products $\&$ services $(15)$

Product attributes (7)

$1^{\text {st. }}$ '[...] Products that are generally perceived as pretty and appealing.' $2^{\text {nd. }}$ ' $[\ldots]$ unhealthy $[\ldots]$ products contaminated with pesticides, both, in gardens and gardening and landscape construction.'

Prices (4)

$1^{\text {st: }: ~ ' R e a s o n a b l e ~ p r i c e s ~}[\ldots]$.'

$2^{\text {nd. ' }}[\ldots]$ overpriced prices in season $[\ldots]$.'

Product-related quality

$1^{\text {st. }}$ 'Freshness [...].'

characteristics (3)

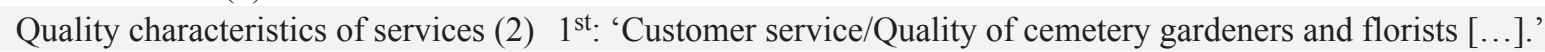

$3^{\text {rd. }}$ Characteristics of consumers (14)

Knowledge \& perception (10)

Interest \& relationship (5)

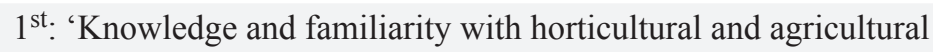
production outside the sector tends towards zero. This lack of knowledge increasingly creates fears and incomprehension, especially with regard to food production. For this reason, the reputation of horticulture is primarily shaped by social opinion leaders outside the sector.'

$2^{\text {nd. }: ~[\ldots . ~ I n n o v a t i o n s ~ a r e ~ h a r d l y ~ n o t i c e d ~ i n ~ s o c i e t y . ~ B a r r i e r s ~ t h a t ~}$ prevent gardeners from innovating are also not perceived (prices, esteem). '

$1^{\text {st: }}$ 'Garden experience at home [...].'

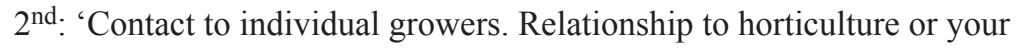
own garden.'

Consciousness \& responsibility (2) $\quad 1^{\text {st: }}$ 'Broad range of consumption in everyday life; effect, use of horticultural products in life (e.g. health effect, fitness, by buying ecological products; the purchase of ecological products makes it possible to assume responsibility in society).'

$4^{\text {th: }}$ Media presence $\&$ public relations work (14)

$1^{\text {st: ' }}$ Call for help to society in crisis situations (e.g. Russia embargo; lack of harvest workers; weather-related failures): intensively marked.' $2^{\text {nd: }}$ 'Professional competence of the representatives, social commitment (local market garden actively communicates with the public, can be visited, invites school classes and kindergarten groups to visit and leads to the plant...).'

$5^{\text {th: }}$ Management methods $\&$ production systems (12)

Plant protection \& fertilization (7) $\quad 1^{\text {st: }}$ 'How it is farmed; as organically farmed fruit and vegetable cultivation shapes the landscape for the customer and negatively affected spray agents are not associated with it.' $2^{\text {nd: }}$ 'Use of fertilizers and pesticides.'

Principles of action \& production $\quad 1^{\text {st. ' }[\ldots] ~ s u s t a i n a b i l i t y, ~ c o n s e r v a t i o n ~ o f ~ r e s o u r c e s . ' ~}$

factors (5)

Production methods (3) $2^{\text {nd: }: ~ '[\ldots] ~ f o i l s ; ~ m o n o c u l t u r e s ~}[\ldots]$. '

$1^{\text {st. ' } O r g a n i c ~ o r ~ c o n v e n t i o n a l . ' ~}$ 
Table 3. Continued.

\begin{tabular}{|c|c|}
\hline Subcategories (n) & Coded text passages/coding \\
\hline \multicolumn{2}{|c|}{$6^{\text {th: }}$ Social responsibility/dealing with nature/environment (9) } \\
\hline & 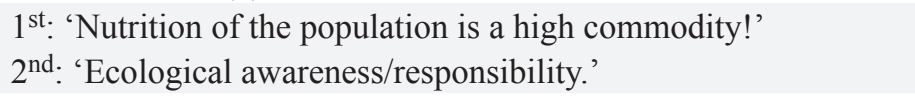 \\
\hline \multicolumn{2}{|l|}{$7^{\text {th: }}$ Social impacts (4) } \\
\hline & $\begin{array}{l}1^{\text {st. ' }} \text { Effects of horticulture on the lives of citizens.' } \\
2^{\text {nd. }} \text { 'Membership/honorary office in organizations/associations.' }\end{array}$ \\
\hline
\end{tabular}

the relevance of the indicators. It is possible that a less frequently mentioned category is also important to respondents, but the respondents did not think of this issue when answering the free text question.

Four further categories could be identified with similar frequencies: 'Products \& services' ( $\mathrm{n}=15)$, 'Characteristics of consumers' ( $\mathrm{n}=14)$, 'Media presence \& public relations work' $(\mathrm{n}=14)$, and 'Management methods \& production systems' $(\mathrm{n}=12)$. Except for the category 'Media presence \& public relations work', it was possible to create further subcategories for each of the categories mentioned.

At least two ('Products \& services' > 'Quality characteristics of services' $(n=2))$ and a maximum of 10 text passages ('Characteristics of consumers' $>$ 'Knowledge \& perception' $(n=10))$ could be assigned to these subcategories. With a total of four subcategories ('Product attributes' $(n=7)$, 'Prices' $(n=4)$, 'Productrelated quality characteristics' $(n=3)$, 'Quality characteristics of Services' $(n=2)$, the 'Products \& services' subcategory has the largest number of subcategories. In this way, the extensive subdivision underlines the relevance of the category in terms of content for the reputation of the sector. The text passages of the characteristic 'Media presence \& public relations work', on the other hand, proved to be so heterogeneous and so diverse that the formation of further subcategories did not appear to be effective. The relevance of the category to reputation is nevertheless underlined. When using this indicator to measure reputation, the questions for the survey should be formulated with particular care. Here it is important to prevent different images and to create a uniform understanding of the indicator. The attributes 'Social responsibility/dealing with nature/environment' $(n=9)$ and 'Social impacts' $(n=4)$ represent effects that go beyond horticultural production. Compared to other sectors (except agriculture), they play a special role in horticulture through the use of natural resources, above particular in the form of outdoor production and the design of public facilities (e.g. urban greening).

The characteristics surveyed correspond in part to the indicators already examined in Sections 4.1 and 4.2. Most surveys referred to the characteristic - 'Job description \& profession' $(n=17)$ - which has not yet been taken into account in this form in the measurement model. The category cannot be clearly differentiated with regard to its direction of action. In addition to text passages that refer to the description of the various horticultural occupations, activities or work processes, it also contains ideas on the part of the stakeholders regarding the company culture, and the behavior/traditions of the sector (e.g. family businesses). It is not always clear whether respondents represent their personal opinions or whether they represent prejudices within society, the job description or the profession. For example, text passages that refer to the attractiveness of working conditions and the level of wage payments must, by definition, be operationalized formatively in the construct. In contrast, text passages that represent prejudices from the consumer's point of view should be assigned to the construct in a reflective direction. In this case an assignment to the category 'Characteristics of consumers' > 'Knowledge \& perception' would be conceivable. The characteristic 'Products \& services' also has an important impact on the reputation of the experts $(n=15)$. The product characteristics $(n=7)$ and the prices $(n=4)$ are of particular relevance here. The indicator was eliminated in Section 4.1 due to a lack of correlation with the global measure. The renewed inclusion of the indicator here by the experts on the open question points to a possible misinterpretation by them in the evaluation in the form of a closed question (cf. Section 6). In particular, the resumption of the indicator should be based on the subcategories, whereby the product characteristics in particular have proven to be particularly relevant $(n=7)$. The interfaces to other 
categories, such as the linking of pesticide-polluted products with the category 'Management methods \& production systems' > 'Plant protection \& fertilization', must not be neglected when measuring reputation. The subcategories of the characteristic 'Characteristics of consumers' are largely covered by the indicators of the reflective direction of action in Section 4.2. However, the experts emphasize the importance of the characteristic 'Knowledge \& perception' $(n=10)$. The cause-and-effect relationship between consumer 'knowledge' and 'relationship' (see Table 3) and the reputation construct cannot be conclusively clarified here. However, an inclusion in the measurement model should take place in any case (Hümmer, 2015: 70). The additions to the reputation construct for horticulture shown in Table 3 should be taken into account for further work. This should be done regardless of whether they are operationalized as an additional indicator or as a specification of an existing indicator in the construct.

\subsection{Reputation map - interaction of the reputation of the segments and the sector}

Horticulture as a sector is characterized by a high degree of heterogeneity. Due to this heterogeneous composition of the sector, the reputation of horticulture from the consumer's point of view can only be determined on the basis of individual segments or product groups. To get a first understanding of the impact of horticultural segments in the public, the experts were asked to characterize the interaction. This way the reputation map can help to better understand and illustrate the interactions between horticulture as a whole and the various segments from the expert's points of view (Figure 2).

The horticultural segments can be shown to have an influence on the reputation of horticulture (X-axis of the reputation map). But the reputation of the segments themselves is also influenced by the reputation of the sector (Y-axis). If an influence can be seen in equal parts, there is an equilibrium (a). Ornamental horticulture is the only segment that is influenced more by the reputation of the sector $(0.57)$ rather than its own reputation impacting upon the sector (0.11). The influence of ornamental horticulture on the reputation of horticulture is therefore negligible. All other segments have a stronger influence on the sector's reputation than their own individual reputations. The influence of horticultural production (fruit growing, vegetable growing, ornamental horticulture and tree nurseries) on the reputation of horticulture is smaller than the influence of service horticulture (retail and floristry, gardening and landscape construction, garden art, cemeteries, parks

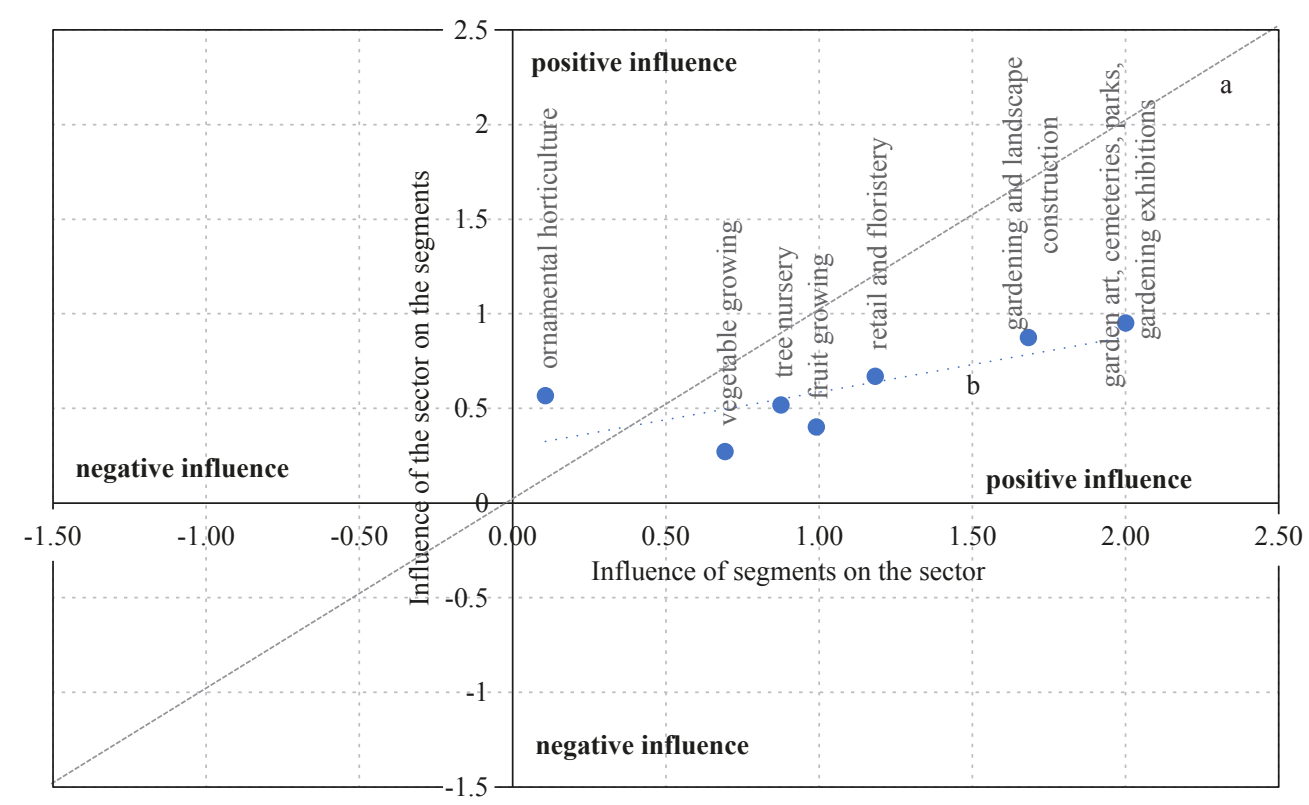

Figure 2. Reputation map ( $\mathrm{n}=102)$.

and gardening exhibitions) on it. The segments gardening and landscape construction (1.67) and garden art, 
cemeteries, parks and garden exhibitions (2) have a much more positive influence on the sector's reputation than the retail and floristry segments (1.18).

In horticultural production, the influence of fruit growing on the sector's reputation (0.99) is most strongly perceived. Vegetable growing, which is the second segment in the food industry of horticulture, has a smaller influence on the reputation of horticulture than fruit growing (0.69).

A comparison between the segments, on the basis of the linear balancing lines (b), shows that service horticulture benefits more from the sector than horticultural production (vegetable growing, fruit growing, tree nurseries).

\section{Discussion}

The experts interviewed here are consultants in horticulture, so they have an internal and external view of the industry. However, the answers are mainly influenced by the experience they have gained in their daily work with gardeners. This means that the reputation, which was considered slightly positive by the experts, cannot be interpreted as a reputation among consumers.

A large number of indicators described in the literature for reputation measurement have been tested by experts for horticulture. There is disagreement in the literature about whether not significant indicators should be removed from the model (Diamantopoulos and Siguaw, 2006: 270). Within a formative construct, the elimination of an indicator could lead to a falsification of the theoretically derived construct (Seltin and Keeves 1994: 4356 citated after Steinmann, 2013: 136). Since the examined indicators show only a very low multicollinearity (VIF), low coefficients $(<0.1)$ as well as the missing significance can be neglected. Due to the almost independent indicators, the effects (coefficients) can be interpreted as a direct result of the respective indicator on the reputation and an elimination does not appear to be necessary.

The limit value of the regression coefficient is also not reached in other empirical studies (Hautzinger, 2009: 231; Helm, 2007a: 245). Especially at Helm (2007a: 246), economic indicators (corporate success, financial performance) have only a weak weight. Steinmann (2013: 136) also points out that the often low regression coefficients for formative indicators may not be misinterpreted.

The indicator 'Product \& service' was eliminated due to the missing correlation with the global measure. In contrast, Raithel and Schwaiger (2015: 947) describe a combination of good reputation, product and service quality and positive customer behavior. For horticulture, the indicator is of particular importance, as contact between consumers and the sector takes place solely via the product and the service (LudwigOhm and Dirksmeyer, 2013: 33). The peculiarity - in comparison to other sectors - is reflected in the lack of perception of producers of food products in the food retail trade. With a share of $92.4 \%$ of fresh fruit and $91.4 \%$ of fresh vegetables, supermarket chains are the dominant sales channel for fruit and vegetables in Germany (AMI, 2019a,b). There the products are not differentiated by brands or companies, but above all by their quality and country of origin. Furthermore, the overall quality of horticultural products cannot be tested at the point of sale by the consumer at the product. In this case, the reputation represents an expectation of the quality of the products (Shapiro, 1982). Thus, the quality of the products and the reputation of the sector influence each other. In contrast, consumer groups who buy horticultural products through direct sales are much more aware of the producer. This means that the distribution channel also has a major influence on the perception of the product and the sector as a whole.

It should also be noted that a lack of knowledge on the part of the consumer regarding the affiliation of products to horticulture can be a substantive reason for eliminating the indicator from the construct. This applies to products that can be grown on both agricultural and horticultural farms, as is the case with field vegetables If products are not linked to the sector, the reputation cannot be influenced by the product or 
the service. In order to be able to take into account the relevance of the indicator in terms of content in the construct, the written additions and explanations of the indicators by the experts are used (cf. Section 4.3).

The literature also describes indicators influenced by reputation. These were also tested for their suitability to be used for measuring reputation in horticulture. There are hints in the literature that a lack of consumer confidence and transparency within the sector is a problem for cooperation in horticulture (Ludwig-Ohm and Dirksmeyer, 2013: 238). However, the indicator 'Trust' was removed from the construct during quality testing because the factor loading was too low. It is possible that experts are currently perceiving higher level of confidence in security of supply than was the case in the past (2012) (Kantar Emnid, 2017: 20). In contrast, Giampietri et al. (2018: 166) show for short food supply chain that 'trust might drive solid relationships between producers and consumers and overcome consumer confusion, building new loyalty [...]'. But trust is formed on the basis of the farmer's reliability and by his/her reputation (Offer, 1997: 451). This underlines the fact that trust and reputation are closely interrelated.

The indicator 'Admiration' was also no longer included in the construct. Fombrun et al. (2015: 7) refer to qualitative studies which show that admiration by stakeholders is generated by good deeds on the part of companies. To this end, Wiedmann (2012: 76) hypothesizes that production output, innovative strength and performance can lead to admiration and appreciation. In this way, the indicator 'Admiration' continues to be captured by formative indicators (e.g. innovation or product and service) in the construct. In addition, the time within the year at which the reputation measurement is executed is also important. The perception or, in particular, admiration of products or services is closely linked to seasonal availability (e.g. regionally grown vegetables or fruit). Asparagus, for example, is very present for many German consumers in spring. Horticultural services can also be used only seasonally (e.g. flowering parks, services in private gardens). Holidays and special occasions (e.g. birthdays, mothers' day) increase the consumer's perception of horticulture (e.g. buying bouquets of flowers) (Schimmenti et al., 2013: 168). On holidays and special occasions, cut flowers are mainly sold through direct sales (Batt and Pool, 2004: 83).

Perhaps trust and admiration are a matter of course for the experts due to their daily work with gardeners. In the literature, it is clear, that these indicators have a close relationship to reputation (Berens and Van Riel, 2004).

The indicator 'Social protest', which also had to be eliminated from the construct, was classified as a reflective indicator according to Albersmeier and Spiller (2010: 266). Accordingly, reputation must be understood as the cause of social protests. In turn, the performance (formative indicators) of a company or a sector are regarded as the cause of reputation. Wiedmann and Buxel (2005) describe the reputation as a reservoir of goodwill that offers potential support in times of crisis and can protect against social protests. Social movements such as protests and boycotts can pose a threat to a company and lead to a deterioration of its reputation, despite simultaneous efforts to create a positive image (Basedeo et al., 2006; McDonnell and King, 2013: 390).

In addition to the indicators determined for reputation measurement in horticulture, the importance of the segments for the reputation of horticulture was determined. In the field of horticultural production, fruit growing has the greatest influence on the reputation of the entire horticultural sector. The service horticulture segments have an even stronger influence on reputation of the entire horticulture sector.

As shown, the contribution of individual segments to the reputation of the sector is very heterogeneous. There are various reasons for this. On the one hand, the achievements of service horticulture are directly visible to society; on the other hand, the products of horticultural production are sold through intermediaries - such as the food retail trade for fruit and vegetables - which means that there is no direct contact with the producer. The concentration in food retailing has led to the development of wholesale food retail chains with enormous purchasing power. They procure fruit and vegetables directly from large farms or buy the products from cooperatives, which have an estimated market share of 40\% (Bijman et al., 2012: 16). As a result of this 
development, the consumer has no contact with producers along the value chain, which is why the influence of fruit and vegetable cultivation on the reputation of the sector is only slight. In addition, negative media reports, such as those that occur in food scandals, can have a negative impact on the trust and reputation of the horticultural food industries (Bitsch et al., 2014: 109-110). In contrast, service horticulture as a whole has positive attributes and is less affected by negative reporting. Priego et al. (2008: 13) show that there is a positive attitude towards public greening in Germany. This study also shows that public green spaces are used significantly more frequently for leisure activities in Germany than in Spain and Chile (Priego et al., 2008: 14-16). These positive links between horticulture and society's leisure activities can have a positive influence on the reputation of the entire sector.

\section{Summary and outlook}

Reputation is a latent construct quantified by formative and reflective indicators. The indicators 'Innovation', 'Customer focus', 'Economic performance', 'Sector development', 'Social responsibility', 'Environmental impact' and 'Communication and presentation in the media' could be identified as the causative factors for the reputation of horticulture (formative side). A correlation with the global measure could be demonstrated for these indicators, which legitimizes their inclusion in the measurement model. They are complemented by the indicators 'Positive attitude to horticulture', 'esteem', 'Location acceptance', 'Consumption of horticultural products', 'Attitude towards horticulture' and 'Relationship to horticulture', the reflective side of the construct. The reflective characteristics show the consequences of the reputation in reality, which are directly reflected in the behavior of consumers towards the sector (Figure 3). These indicators, which originate from other sectors and companies, are supplemented by horticultural-specific reputation characteristics. Developed on the basis of an open question to the experts, eight characteristics emerged within the framework of inductive category formation, of which a total of seven are taken into account. 'Job description \& profession', 'Products \& services', 'Characteristics of consumers', 'Media presence \& public relations work', 'Management methods \& production systems', 'Social responsibility/dealing with nature/environment' and 'Social impacts' must be included to complete the construct. The formed categories could to a large extent be subdivided into further subcategories. These provide indications of the main focuses that should be set for a reputation measurement and that should help to interpret the characteristics logically. The subcategory 'Characteristics of consumers' $>$ 'Knowledge \& perception' represents the most frequently mentioned of all subcategories $(\mathrm{n}=10)$ and should be adequately mapped according to its possible characteristics. The Reputation Map shows the interactions

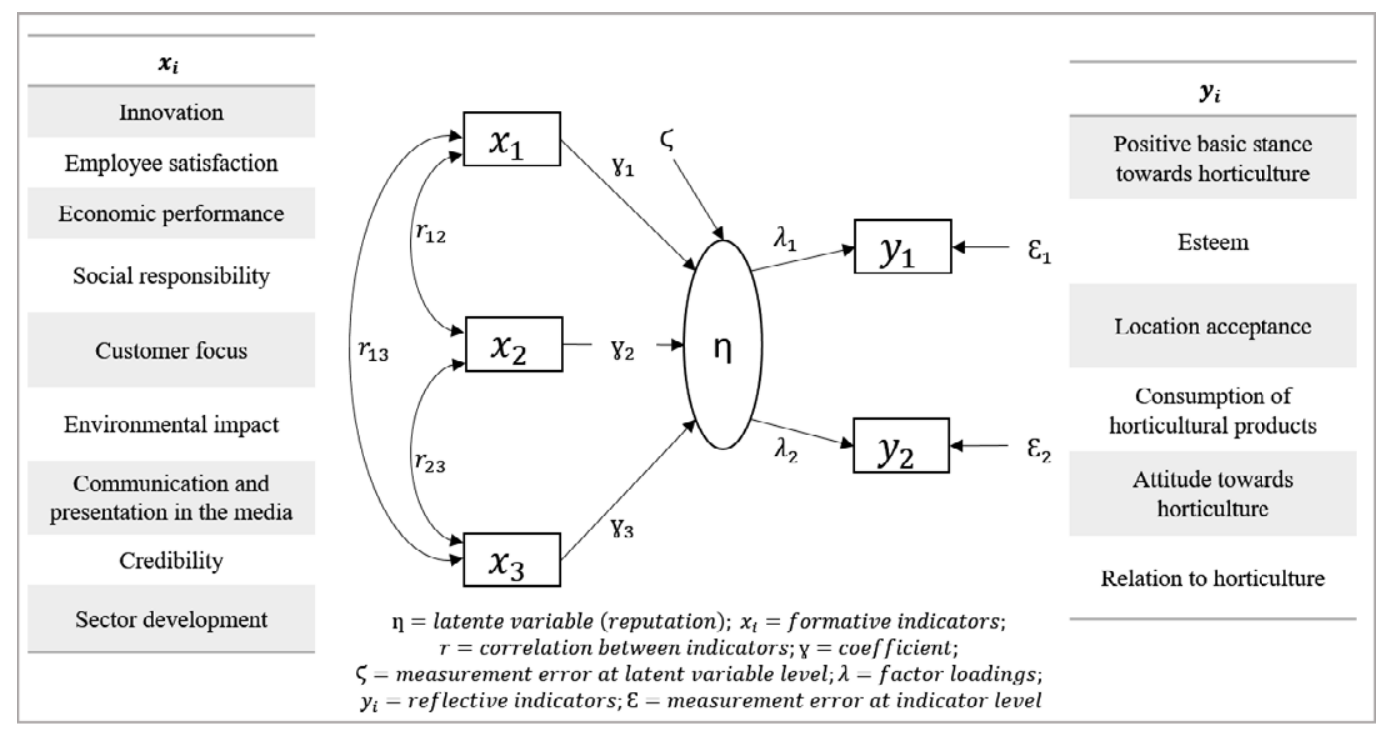

Figure 3. Validated structural model based on quantitative answer on the expert survey (Adapted from Diamantopoulos and Winklhofer, 2001: 272). 
between the reputation of the segments and the reputation of their sector. The service and retail segment proved to be particularly relevant to the reputation of horticulture. On the other hand, the horticultural production segments had only a minor influence on the sector's reputation.

With the results of the present study, a statistically validated model for reputation measurement could be developed and adapted to horticulture. In contrast to what could be expected from the literature research, the experts estimate the reputation of horticulture in society as slightly positive.

The extent to which the horticultural-specific reputation characteristics should be combined with the indicators from the quality test must be examined in detail before a final reputation measurement among consumers is carried out. Some of the indicators can be adapted, others can be specified more precisely and others newly created. In a step preceding the reputation measurement, the determination of the direction of effect, of the characteristics generated specifically for the sector, represents an important task. A misinterpretation of these leads to incorrect and inaccurate assumptions in the model, which in turn can lead to a distortion of the results. Other empirical studies have also pointed to the importance of processes of adaptation and specification of the indicators (Hautzinger, 2009: 202; Helm, 2007c: 273). Both studies use multi-stage pretests to ensure that the indicators are assigned to the construct in terms of content. During this adjustment process, care should be taken to ensure that, by and large, the indicators completely reflect the content of the reputation construct (Diamantopoulos and Siguaw, 2006: 271). Once this procedure is complete, the resulting construct can be used to measure the reputation of the horticultural sector. For latent constructs, a measurement using multi-item scales is recommended in the literature (Diamantopoulos and Siguaw, 2006; Schwaiger, 2004: 57). The indicators are operationalized by several items or statements and serve as a basis for the development of a consumer survey. A survey of consumers requires their knowledge of the horticultural sector and its products. In this way, 'knowledge' and the availability of information influence the assessment of the respondent of the company or sector to be evaluated (Newburry, 2010: 392). A survey of consumers should therefore be based on the results of the reputation map. Finally, the results of a consumer study can serve as a basis for deriving recommendations for action for the sector. The indicators identified here represent the key parameters of reputation. The impact of these indicators on the reputation of horticulture can only be determined after the consumer survey. Knowledge of the influence of the individual indicators enables producers to influence the reputation of the sector.

\section{Supplementary material}

Supplementary material can be found online at https://doi.org/10.22434/IFAMR2020.0009

Questionnaire for horticultural consultants

\section{References}

Albersmeier, F. and A. Spiller. 2010. Die reputation der Fleischwirtschaft: eine Kausalanalyse. German Journal of Agricultural Economics 59(4): 258-270.

Agrarmarkt Informations Gesellschaft mbH (AMI). 2019a. AMI Markt Bilanz Obst 2019. AMI, Bonn, Germany. Agrarmarkt Informations Gesellschaft mbH (AMI). 2019b. AMI Markt Bilanz Gemüse 2019. AMI, Bonn, Germany.

Basedeo, D.K., K.G. Smith, C.M. Grimm, V.P. Rindova and P.J. Derfus. 2006. The impact of market actions on firm reputation. Strategic Management Journal 27(1): 1205-1219.

Batt, P.J. and J. Pool. 2004. Consumer preferences for cut flowers in western Australia. Acta Horticulturae 655: 81-88.

Berens, G. and C.B.M. Van Riel. 2004. Corporate associations in the academic literature: three main streams of thought in the reputation measurement literature. Corporate Reputation Review 7(2): 161-178.

Bijman, J., P. Pyykkönen and P. Ollila. 2012. Support for farmers' cooperatives. Wageningen UR, Wageningen, the Netherlands. 
Bitsch, V., N. Kokovic and M. Rombach. 2014. Risk communication and market effects during foodborne illnesses: a comparative vase study of bacterial outbreaks in the U.S. and in Germany. International Food and Agribusiness Management Review 17(3): 97-114.

Boyd, B.K., D.D. Bergh and D.J. Ketchen. 2010. Reconsidering the reputation-performance relationship: a resource-based view. Journal of Management 36(3): 588-609.

Breyer, P.O. 1962. Ruf und Rufpolitik. Eine Studie über das Wesen des Rufes und der betriebswirtschaftlichen Rufpolitik. Mannheim, Germany.

Davies, G., R. Chun, R.V. Da Silva and S. Roper. 2001. The personification metaphor as a measurement approach for corporate reputation. Corporate Reputation Review 4(2): 113-127.

Diamantopoulos, A., P. Riefler and K.P. Roth. 2008. Advancing formative measurement models. Journal of Business Research 61(12): 1203-1218.

Diamantopoulos, A. and J.A. Siguaw. 2006. Formative versus reflective indicators in organizational measure development: a comparison and empirical illustration. British Journal of Management 17(4): 263-282.

Diamantopoulos, A. and H.M. Winklhofer. 2001. Index construction with formative indicators: an alternative to scale development. Journal of Marketing Research 38(2): 269-277.

Emnid, K. 2017. Das Image der Deutschen Landwirtschaft. Available at: http://media.repro-mayr.de/79/668279. pdf

Fombrun, C.J. 1996. Reputation: realizing value from the corporate image. Havard Business School Press, Boston, MA, USA.

Fombrun, C.J., L.J. Ponzi and W. Newburry. 2015. Stakeholder tracking and analysis: the RepTrak® system for measuring corporate reputation. Corporate Reputation Review 18(1): 3-24.

Fombrun, C. and M. Shanley. 1990. What's in a name? Reputation building and corporate strategy. Academy of Management Journal 33(2): 233-258.

Fornell, C. and F.L. Bookstein. 1982. Two structural equation models: LISREL and PLS applied to consumer exit-voice theory. Journal of Marketing Research 19(4): 440-452.

Fornell, C. and D.F. Larcker. 1981. Evaluating structural equation models with unobservable variables and measurement error. Journal of Marketing Research 18(1): 39-50.

Giampietri, E., F. Verneau, T. Del Giudice, V. Carfora and A. Finco. 2018. A theory of planned behaviour perspective for investigating the role of trust in consumer purchasing decision related to short food supply chains. Food Quality and Preference 64: 160-166.

Gujarati, D.N. 2004. Basic econometrics. McGraw-Hill, New York, NY, USA.

Hauser, R.M. and A.S. Goldberger. 1971. The treatment of unobservable variables in path analysis. Sociological Methodology 3: 81-117.

Hautzinger, H. 2009. Der Rufvon Branchen - Eine empirische Untersuchung zur Messung, Wechselwirkung und Handlungsrelevanz der Branchenreputation. Gabler, Wiesbaden, Germany.

Helm, S. 2005. Designing a formative measure for corporate reputation. Corporate Reputation Review 8(2): 95-109.

Helm, S. 2007a. One reputation or many? Comparing stakeholders' perceptions of corporate reputation. Corporate Communications: an International Journal 12(3): 238-254.

Helm, S. 2007b. The role of corporate reputation in determining investor satisfaction and loyalty. Corporate Reputation Review 10(1): 22.

Helm, S. 2007c. Unternehmensreputation und Stakeholder-Loyalität. Deutscher Universitäts-Verlag, Wiesbaden, Germany.

Huber, F., A. Herrmann, F. Meyer, J. Vogel and K. Vollhardt. 2003. Kausalmodellierung mit partial least squares. Gabler, Wiesbaden, Germany.

Hümmer, C. 2015. Die Reputation interner Dienstleister innerhalb eines Konzerns. Springer Gabler, Düsseldorf, Germany.

Joreskog, K.G. and A.S. Goldberger. 1975. Estimation of a model with multiple indicators and multiple causes of a single latent variable. Journal of the American Statistical Association 70(351): 631-639.

Keh, H.T. and Y. Xie. 2009. Corporate reputation and customer behavioral intentions: the roles of trust, identification and commitment. Industrial Marketing Management 38(7): 732-742.

Lal, R. 2008. Sustainable horticulture and resource management. Acta Horticulturae 767: 19-43. 
Liebert, T. 2009. Das Image der Landwirtschaft: Ist und Wege zum Soll. Systematische Differenzierungen und kommunikationsstrategische Ableitungen aus empirischen Befunden. In: J. Böhm, F. Albersmeier and A. Spiller (eds.) Die Ernährungswirtschaft im Scheinwerferlicht der Öffentlichkeit - Reihe Agrarökonomie. EUL Verlag, Göttingen, Germany, pp. 25-46.

Lins, K.V., H. Servaes and A. Tamayo. 2017. Social capital, trust, and firm performance: the value of corporate social responsibility during the financial crisis. Journal of Finance 72(4): 1785-1824.

Ludwig-Ohm, S. and W. Dirksmeyer. 2013. Ausgewählte Analyse zu den Rahmenbedingungen und zur Wettbewerbsfähigkeit des Gartenbaus in Deutschland. Thünen Working Paper 6, Braunschweig, Germany.

Luoma-aho, V. 2008. Sector reputation and public organisations. International Journal of Public Sector Management 21(5): 446-467.

MacMillan, K., K. Money, S. Downing and C. Hillenbrand. 2005. Reputation in relationships: measuring experiences, emotions and behaviors. Corporate Reputation Review 8(3): 214-231.

Mayring, P. 2014. Qualitative content analysis: theoretical foundation, basic procedures and software solution. Klagenfurth, Germany.

McDonnell, M.H. and B. King. 2013. Keeping up appearances: reputational threat and impression management after social movement boycotts. Administrative Science Quarterly 58(3): 387-419.

Meyerding, S.G.H. 2016. Change management study of horticulture 2015 - conditions and success factors. Journal of Organisational Transformation and Social Change 13(2): 123-146.

Newburry, W. 2010. Reputation and supportive behavior: moderating impacts of foreignness, industry and local exposure. Corporate Reputation Review 12(4): 388-405.

Nitzl, C. 2010. Eine anwenderorientierte Einführung in partial least square (PLS)-methode. Institut für Industrielles Management, Arbeitspapier Nr. 21, Hamburg, Germany.

Offer, A. 1997. Between the gift and the market: the economy of regard. Economic History Review 50(3): 450-476.

Peterson, R.A. 1994. Coefficient alpha. Journal of Consumer Research 21: 381-391.

Petty, R.E. and J.T. Cacioppo. 1986. Communication and persuasion: central and peripheral routes to attitude change. Springer Verlag, New York, NY, USA.

Priego, C., J.H. Breuste and J. Rojas. 2008. Perception and value of nature in urban landscapes: a comparative analysis of cities in Germany, Chile and Spain. Landscape Online 7(1): 1-22.

Raithel, S. and M. Schwaiger. 2015. The effects of corporate reputation perceptions of the general public on shareholder value. Academy of Management Journal 36: 945-956.

Roberts, P.W. and G.R. Dowling. 2002. Corporate reputation and sustained superior financial performance. Strategic Management Journal 23(12): 1077-1093.

Rossiter, J.E. 2002. The C-OA-SE procedure for scale development in marketing. International Journal of Research in Marketing 19(4): 305-335.

Sageder, M., C. Mitter and B. Feldbauer-Durstmüller. 2018. Image and reputation of family firms: a systematic literature review of the state of research. Review of Managerial Science 12(1): 335-377.

Schimmenti, E., A. Galati, V. Borsellino, C. Ievoli, C. Lupi and S. Tinervia. 2013. Behaviour of consumers of conventional and organic flowers and ornamental plants in Italy. Horticultural Science 40(4): 162-171.

Schöps, J. 2012. Drivers for customer satisfaction within the traditional German horticultural retail. Acta Horticulturae 930: 175-182.

Schöps, J. 2013. Kundenzufriedenheit in direkt absetzenden Einzelhandelsgärtnereien. PhD-thesis, Technische Universität München, München, Germany.

Schwaiger, M. 2004. Components and parameters of corporate reputation - an empirical study. Schmalenbach Business Review 56(1): 46-71.

Schwalbach, J. 2003. Unternehmensreputation als Erfolgsfaktor. In: M. Rese (ed.) Relationship marketing. Springer, Berlin Heidelberg, Germany, pp. 225-238.

Seltin, N. and J. Keeves. 1994: Path analysis with latent variables. In: T. Husen and T. Postlethwaite (eds.) The International Encyclopedia of Education. Oxford, UK, pp. 4352-4359.

Shapiro, C. 1982. Consumer information, product quality, and seller reputation. The Bell Journal of Economics 13(1): 20-35. 
Steinmann, T. 2013. Vertrauen in banken: eine empirische untersuchung von determinanten und konsequenzen. Springer Gabler, Berlin, Germany.

Storck, H. 1992. Die künftigen Aufgaben der Gartenbauökonomie - Podiumsdiskussion. In: H. Storck (ed.) Die Gartenbaü̈konomie - heute und morgen. Institut für Gartenbauökonomie, Hannover, Germany, pp. 43-52.

Straub, D.W. 1989. Validating instruments in MIS research. MIS Quarterly 13(2): 147-169.

Wartick, S.L. 2002. Measuring corporate reputation: definition and data. Business \& Society 41(4): 371-392.

Weigelt, K. and C. Camerer. 1988. Reputation and corporate strategy: a review of recent theory and applications. Strategic Management Journal 9(5): 443-454.

Wiedmann, K.P. 2012. Ansatzpunkte zur Messung der Unternehmensreputation als Grundlage einer Erfolg versprechenden Reputationsmanagementplanung - Das RepTrak-Konzept als Ausgangspunkt und Skizzen zur relevanten Weiterentwicklung. In: C. Wüst and R.T. Kreutzer (eds.) Corporate reputation management. Springer Gabler, Wiesbaden, Germany, pp. 57-103.

Wiedmann, K.P., C. Fombrun and C.B.M. Van Riel. 2007. Reputationsanalyse mit dem Reputation Quotient. In: M. Piwinger and A. Zerfass (eds.) Corporate reputation management. Gabler, Wiesbaden, Germany, pp. 321-337.

Wiedmann, K.P. and H. Buxel. 2005. Corporate reputation management in Germany: results of an empirical study. Corporate Reputation Review 8(2): 145-163.

Winfree, J.A. and J.J. McCluskey. 2005. Collective reputation and quality. American Journal of Agricultural Economics 81(1): 206-213.

Zinnbauer, M. and M. Eberl. 2004. Die Überprüfung von Spezifikation und Güte von Strukturgleichungsmodellen: Verfahren und Anwendung. Schriften zur empirischen Forschung und quantitativen Unternehmensplanung (Heft 21). Ludwig-Maximilians-Universität München, München, Germany. 